\title{
Efeito da base genética materna e da estação de parição sobre variáveis produtivas de fêmeas primíparas Holandês $x$ Zebu
}

\author{
[Effect of the maternal genetic basis and of the calving season on productive variables of \\ primiparous Holstein $x$ Zebu cows]

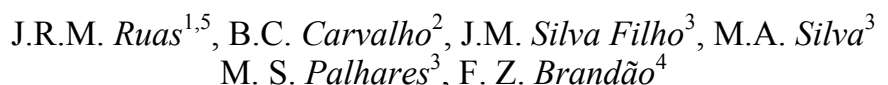 \\ ${ }^{1}$ EPAMIG - Viçosa, MG \\ ${ }^{2}$ Aluno de pós-graduação - EV-UFMG - Belo Horizonte, MG \\ ${ }^{3}$ Escola de Veterinária - UFMG \\ Caixa Postal 567 \\ 30123-970 - Belo Horizonte, MG \\ ${ }^{4}$ Faculdade de Veterinária - UFF - Niterói, RJ \\ ${ }^{5}$ Bolsista do $\mathrm{CNPq}$ \\ RESUMO
}

\begin{abstract}
Avaliaram-se variáveis produtivas de 78 fêmeas primíparas mestiças de base genética materna Gir ou Guzerá, paridas na estação seca ou chuvosa, utilizando-se o procedimento GLM do SAS. A estação de parição interferiu $(\mathrm{P}<0,05)$ no peso ao parto $(\mathrm{PP})$, no escore da condição corporal ao parto (ECCP), no ganho de peso durante a gestação, no período de serviço (PS) e no intervalo de partos (IDP). O PP e ECCP foram maiores $(\mathrm{P}<0,05)$ nas primíparas que pariram na estação seca em relação às que pariram na estação chuvosa. Os valores foram de $475,19 \pm 39,81 \mathrm{~kg}, 4,07 \pm 0,44$ e $420,67 \pm 37,80 \mathrm{~kg}$ e $3,62 \pm 0,37$, respectivamente, para a estação seca e chuvosa. O PS e o IDP foram menores $(\mathrm{P}<0,05)$ entre as vacas que pariram na estação seca, 132,02 $\pm 91,94$ dias

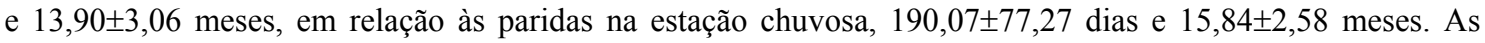
fêmeas de base genética Gir apresentaram melhor desempenho $(\mathrm{P}<0,05)$ que as de base genética Guzerá para as características produção de leite, duração da lactação e produção de leite por dia de intervalo de partos, cujos valores, nessa ordem, foram de $2276,15 \pm 656,47 \mathrm{~kg}, 306,08 \pm 46,55 \mathrm{dias}, 5,06 \pm 1,38 \mathrm{~kg} / \mathrm{dia}$ para as fêmeas de base

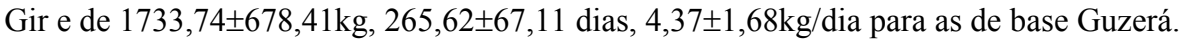

Palavras-chave: gado leiteiro, Hostein x Zebu, produção de leite, eficiência reprodutiva, base genética, estação de parição

\begin{abstract}
Productive variables of 78 crossbred Holstein $x$ Zebu primiparous cows of Gir or Guzera maternal genetic basis, calved in the dry or rainy season were evaluated using the GLM procedure of the SAS. The calving season affected the weight at calving (WC), body condition score at calving (BCS), service period (SP) and calving interval (CI). The WC and BCS were higher $(P<0.05)$ por cows calved in the dry season, $475.19 \pm 39.81 \mathrm{~kg}$ and $4.07 \pm 0.44$, than in the rainy season, $420.67 \pm 37.80 \mathrm{~kg}$ and $3.62 \pm 0.37$, respectively. The $S P$ and $C I$ were shorter $(P<0.05)$ for cows calved in the dry season, $132.02 \pm 91.94$ days and $13.90 \pm 3.06$ months, than cows calved in the rainy season, $190.07 \pm 77.27$ days e 15.84 \pm 2.58 months, respectively. The Gir based cows had higher milk yield, longer lactation period and higher milk yield per day of calving interval than the Guzera based cows, respectively, 2276.15 $\pm 656.47 \mathrm{~kg}, 306.08 \pm 46.55$ days, $5.06 \pm 1.38 \mathrm{~kg} /$ day for the Gir and $1733.74 \pm 678.41 \mathrm{~kg}, 265.62 \pm 67.11$ days, $4.37 \pm 1.68 \mathrm{~kg} /$ day for the Guzera based cows.
\end{abstract}

Keywords: dairy cattle, Holstein x Zebu, milk yield, reproductive traits, genetic basis, season calving

Recebido em 28 de julho de 2005

Aceito em 10 de novembro de 2006

E-mail: jrmruas@epamig.ufv.br

Apoio: FAPEMIG/CAG 114/01 e 350/04 


\section{INTRODUÇÃO}

A produção de leite no Brasil apresenta um cenário contrastante. $\mathrm{O}$ rebanho bovino leiteiro, composto por cerca de 20 milhões de vacas, produz em torno de 21 bilhões de litros de leite por ano. Esse rebanho é composto por apenas $6 \%$ de vacas especializadas, que produzem em média $4500 \mathrm{~kg}$ de leite por lactação. A grande maioria do rebanho, $74 \%$, é composta de vacas mestiças, com produção média de $1100 \mathrm{~kg}$ por lactação, enquanto que os $20 \%$ restantes são de vacas sem qualquer especialização, com produção média de $600 \mathrm{~kg}$ por lactação (Vilela, 2003). A composição do rebanho leiteiro nacional reflete as profundas diferenças existentes nos diferentes sistemas de produção.

Apesar de alguns trabalhos na literatura estudarem os sistemas de produção com gado mestiço leiteiro F1 Holandês x Zebu (Freitas et al., 2001; Saulytis, 2004), algumas características de grande importância, como o peso à cobrição e ao primeiro parto, ainda não foram bem avaliadas. De igual forma, há muito a se conhecer sobre o sistema de recria das novilhas. Além disso, poucos trabalhos na literatura nacional têm comparado o efeito da base genética materna zebuína e da estação de parição sobre diferentes variáveis produtivas. $\mathrm{O}$ objetivo deste trabalho foi avaliar o efeito da base genética materna Gir ou Guzerá, e da estação de parição, estação seca ou chuvosa, sobre variáveis produtivas de fêmeas primíparas Holandês $\mathrm{x}$ Zebu .

\section{MATERIAL E MÉTODOS}

Utilizaram-se 78 novilhas mestiças Holandês $\mathrm{x}$ Zebu, de duas bases genéticas maternas distintas, sendo 40 novilhas F1 Holandês x Gir e 38 novilhas mestiças F1 Holandês x Guzerá. A média de idade dos animais foi de 10,43 $\pm 2,02$ e $10,74 \pm 0,84$ meses, com pesos de $174,13 \pm 14,30$ e $191,76 \pm 21,08 \mathrm{~kg}$, para as novilhas de base genética Gir e Guzerá, respectivamente. Elas foram recriadas em pastagens de Brachiaria decumbens e B. brizantha e suplementadas com mistura múltipla durante a primeira estação seca após a desmama. $\mathrm{Na}$ estação chuvosa consecutiva, apenas 44 novilhas foram suplementadas. Elas foram submetidas à estação de monta (EM) a partir do peso vivo mínimo de $320 \mathrm{~kg}$. Foram consideradas duas estações de monta, uma na estação seca e outra na estação chuvosa, o que resultou em duas estações de parição. A distribuição dos animais pode ser vista na Tab. 1.

Tabela 1. Distribuição das novilhas mestiças F1 Holandês x Zebu utilizadas no experimento, de acordo com a base genética materna, suplementação oferecida durante a recria e época do parto

\begin{tabular}{lccccccc} 
& \multicolumn{5}{c}{ Suplementação durante a recria } & \multicolumn{4}{c}{ Estações seca e chuvosa } \\
\cline { 2 - 6 } & \multicolumn{5}{c}{ Estação seca } & \multicolumn{5}{c}{ Total } \\
\cline { 2 - 7 } & Hol x Gir & Hol x Guzerá & Sub-total & Hol x Gir & Hol x Guzerá & Sub-total & \\
\hline Estação seca & 8 & 12 & 20 & 13 & 15 & 28 & 48 \\
Estação chuvosa & 10 & 4 & 14 & 9 & 7 & 16 & 30 \\
Total & 18 & 16 & 34 & 22 & 22 & 44 & 78 \\
\hline
\end{tabular}

Após o diagnóstico de gestação, as novilhas permaneceram em pastagens de $B$. decumbens e $B$. brizantha, onde recebiam mistura mineral à vontade, até 30 dias antes do parto, quando foram transferidas para piquete maternidade e pesadas mensalmente, até o parto. Nessa ocasião, avaliou-se também o escore da condição corporal, numa escala de 3 a 5 (Ruas, 2000). Após o parto, as primíparas foram colocadas em lote de animais em início de lactação e incorporadas no manejo normal de ordenha e alimentação da fazenda, juntamente com os animais de outras ordens de lactação. As fêmeas foram submetidas a duas ordenhas diárias, com a presença do bezerro. A ordenha, controle leiteiro e secagem dos animais seguiram recomendações de rotina para experimentos dessa natureza.

As vacas foram alimentadas durante a estação seca com silagem de milho e/ou cana-de-açúcar. $\mathrm{Na}$ estação chuvosa, foram mantidas em pastagens de $B$. decumbens e $B$. brizantha. O concentrado foi fornecido durante a ordenha de acordo com a produção de leite e o manejo reprodutivo adotado foi o da monta natural. As vacas foram colocadas com os touros logo após o parto. Foram realizados, mensalmente, diagnósticos de gestação, além de avaliações ginecológicas nas vacas que não apresentaram cio após 120 dias de lactação. 
As seguintes variáveis foram avaliadas: idade (IC) e peso (PC) à cobrição; ganho de peso durante a gestação (GPG); idade (IP) e peso (PP) ao parto; escore da condição corporal ao parto (ECCP); produção de leite nos primeiros 100 dias de lactação (PL100); produção de leite na primeira lactação (PL); duração da lactação (DL); produção de leite média na primeira lactação (PLM); produção de leite por dia de intervalo de partos (PLDIP); período de serviço (PS) e intervalo de partos (IDP).

Os dados foram submetidos à análise de variância, utilizando-se o procedimento GLM do SAS, versão 2000. No modelo utilizado consideraram-se os efeitos fixos da base genética materna, Gir ou Guzerá, suplementação oferecida durante a recria, suplementado ou não na estação chuvosa, e estação de parição, estação seca ou chuvosa, bem como todas as suas interações, além da covariável idade no início da suplementação. As médias foram comparadas pelo teste F ou t de Student.

\section{RESULTADOS E DISCUSSÃO}

Na Tab. 2 apresenta-se a significância dos efeitos fixos incluídos nos diferentes modelos para avaliar as variáveis biométricas, produtivas e reprodutivas de fêmeas F1 Holandês x Zebu.

Tabela 2. Valores de significância $(\mathrm{P})$ da base genética materna, da suplementação durante a recria e da estação de parição e suas interações e da covariável idade inicial sobre variáveis biométricas, produtivas e reprodutivas de fêmeas primíparas F1 Holandês x Zebu

\begin{tabular}{|c|c|c|c|c|c|c|c|c|c|}
\hline Variável $^{1}$ & $\begin{array}{c}\text { Base } \\
\text { genética } \\
\text { (B) }\end{array}$ & $\begin{array}{l}\text { Suple- } \\
\text { mentação } \\
\text { (S) }\end{array}$ & $\begin{array}{l}\text { Época do } \\
\text { parto }(E)\end{array}$ & $\begin{array}{l}\text { Idade } \\
\text { inicial }\end{array}$ & $B \times S$ & $B \times E$ & $\mathrm{~S} \times \mathrm{E}$ & $\mathrm{B} \times \mathrm{S} \times \mathrm{E}$ & $\mathrm{CV}$ \\
\hline $\mathrm{IC}$ & 0,0053 & 0,2240 & 0,0150 & 0,0809 & 0,2669 & 0,0054 & 0,1035 & 0,2633 & 12,93 \\
\hline $\mathrm{PC}$ & 0,2801 & 0,9831 & 0,1216 & 0,8203 & 0,2722 & 0,2291 & 0,6641 & 0,6901 & 9,23 \\
\hline IP & 0,0036 & 0,2009 & 0,0110 & 0,0579 & 0,2517 & 0,0048 & 0,1012 & 0,2659 & 9,15 \\
\hline PP & 0,8983 & 0,3457 & 0,0001 & 0,0580 & 0,7341 & 0,9047 & 0,2903 & 0,3227 & 8,66 \\
\hline GPG & 0,2244 & 0,2830 & 0,0001 & 0,0136 & 0,5102 & 0,1817 & 0,0998 & 0,3336 & 36,33 \\
\hline ECCP & 0,2927 & 0,2767 & 0,0164 & 0,1864 & 0,7489 & 0,8403 & 0,9358 & 0,4446 & 10,50 \\
\hline PL100 & 0,2159 & 0,3794 & 0,0117 & 0,0294 & 0,2627 & 0,2076 & 0,3879 & 0,5781 & 19,54 \\
\hline PL & 0,0005 & 0,1649 & 0,9817 & 0,0108 & 0,3691 & 0,4230 & 0,9550 & 0,7651 & 32,55 \\
\hline DL & 0,0024 & 0,2059 & 0,4758 & 0,0294 & 0,2627 & 0,2076 & 0,3879 & 0,5781 & 19,54 \\
\hline PLM & 0,0487 & 0,6593 & 0,6783 & 0,1397 & 0,6445 & 0,8597 & 0,7721 & 0,9938 & 27,76 \\
\hline PLDIP & 0,0231 & 0,5001 & 0,1333 & 0,0325 & 0,6391 & 0,6358 & 0,6699 & 0,8682 & 31,69 \\
\hline PS & 0,2327 & 0,8259 & 0,0093 & 0,8107 & 0,1915 & 0,5476 & 0,2934 & 0,5298 & 57,49 \\
\hline IDP & 0,2326 & 0,8249 & 0,0093 & 0,8114 & 0,1919 & 0,5471 & 0,2941 & 0,5309 & 20,08 \\
\hline
\end{tabular}

${ }^{1}$ IC - idade à cobrição; PC - peso à cobrição; IP - idade ao parto; PP - peso ao parto; GPG -ganho de peso durante a gestação; ECCP - escore da condição corporal ao parto; PL100 - produção de leite nos primeiros 100 dias de lactação; PL - produção de leite na primeira lactação; PLM - produção de leite média; PLDIP - produção de leite por dia de intervalo de partos; PS - período de serviço; IDP - intervalo de partos.

A suplementação durante a recria não influenciou $(\mathrm{P}>0,05)$ nenhuma das variáveis estudadas. Todavia, tanto a base genética materna quanto a época do parto exerceram efeito $(\mathrm{P}<0,05)$ sobre diferentes variáveis. A época do parto influenciou $(\mathrm{P}<0,05)$ as variáveis peso ao parto $(\mathrm{PP})$, ganho de peso durante a gestação (GPG), escore da condição corporal ao parto (ECCP), produção de leite nos primeiros 100 dias de lactação (PL100), período de serviço (PS) e intervalo de partos (IDP), havendo interação época do parto versus base genética materna para as variáveis idade à cobrição (IC) e idade ao parto (IP). Na Tab. 3 apresentam-se os valores das diferentes variáveis avaliadas em função da época do parto.

Um dos principais efeitos da época do parto foi sobre a condição nutricional no pré-parto das primíparas. Novilhas cobertas durante a estação seca, e que pariram no início da estação seca consecutiva, tiveram a maior parte da gestação durante a estação chuvosa, época de maior disponibilidade e qualidade das pastagens. Ao contrário, nas novilhas cobertas durante a estação chuvosa, a gestação transcorreu durante a estação seca. Assim, para as primíparas que pariram na estação seca, o ganho de peso durante a gestação, de $114,44 \pm 27,92 \mathrm{~kg}$, foi maior $(\mathrm{P}<0,05)$ do que o de $45,10 \pm 41,73 \mathrm{~kg}$ apresentado pelas que pariram na estação chuvosa. A diferença no ganho de peso durante a gestação refletiu em maiores $(\mathrm{P}<0,05)$ peso e escore da condição corporal ao parto nas primíparas que pariram na estação seca, que apresentaram peso ao parto de $475,19 \pm 39,81 \mathrm{~kg}$ e escore corporal de 4,07 $\pm 0,44$, ambos maiores $(\mathrm{P}<0,05)$ do que os obtidos pelas fêmeas que pariram na estação chuvosa, $420,67 \pm 37,80 \mathrm{~kg}$ e $3,62 \pm 0,37$. 
Efeito da base genética materna...

Tabela 3. Valores médios de variáveis biométricas, produtivas e reprodutivas de primíparas F1 Holandês $\mathrm{x}$ Zebu com partos ocorridos nas estações seca ou chuvosa

\begin{tabular}{lcc}
\hline Variável & Estação seca & Estação chuvosa \\
\hline PC (kg) & $360,75 \pm 22,83$ & $376,66 \pm 45,40$ \\
PP (kg) & $475,19 \pm 39,81 \mathrm{a}$ & $420,67 \pm 37,80 \mathrm{~b}$ \\
GPG (kg) & $114,44 \pm 27,92 \mathrm{a}$ & $45,10 \pm 41,73 \mathrm{~b}$ \\
ECCP (3-5) & $4,07 \pm 0,44 \mathrm{a}$ & $3,62 \pm 0,37 \mathrm{~b}$ \\
PL100 (kg) & $766,78 \pm 209,85 \mathrm{a}$ & $920,35 \pm 211,05 \mathrm{~b}$ \\
PL (kg) & $2006,80 \pm 743,85$ & $2052,00 \pm 678,63$ \\
PLM (kg/dia) & $7,04 \pm 2,13$ & $6,91 \pm 1,52$ \\
DL (dias) & $282,39 \pm 53,26$ & $295,48 \pm 70,76$ \\
PS (dias) & $132,02 \pm 91,94 \mathrm{a}$ & $190,07 \pm 77,27 \mathrm{~b}$ \\
IDP (meses) & $13,90 \pm 3,06 \mathrm{a}$ & $15,84 \pm 2,58 \mathrm{~b}$ \\
PLDIP (kg/dia) & $4,94 \pm 1,58$ & $4,40 \pm 1,46$ \\
\hline
\end{tabular}

Médias na mesma linha seguidas de letras distintas diferem entre si $(\mathrm{P}<0,05)$ pelo teste $\mathrm{F}$.

PC-peso à cobrição; PP-peso ao parto; GPG-ganho de peso durante a gestação; ECCP-escore da condição corporal ao parto; PL100-produção de leite nos primeiros 100 dias de lactação; PL-produção de leite na primeira lactação; PLM-produção de leite média; DL-dias da lactação; PS-período de serviço; IDP-intervalo de partos; PLDIPprodução de leite por dia de intervalo de partos.

A produção de leite nos primeiros 100 dias de lactação foi maior $(\mathrm{P}<0,05)$ para as primíparas que pariram na estação chuvosa, $920,35 \pm 211,05 \mathrm{~kg}$, em relação às que pariram na estação seca, $766,78 \pm 209,85 \mathrm{~kg}$, embora apresentassem menores peso e escore da condição corporal ao parto (Tab. 3). Essa diferença na produção parcial de leite pode ser explicada pela diferença na composição bromatológica dos alimentos entre as duas épocas do ano. Para as vacas que pariram na estação chuvosa, o volumoso era oferecido na forma de pastagens de Brachiaria decumbens e $B$. brizantha, enquanto que na estação seca foi oferecida silagem de milho aos animais em início de lactação. As pastagens, durante a estação chuvosa, apresentam elevado teor de proteína bruta e carboidratos solúveis, associados a moderadas concentrações de fibra em detergente neutro (FDN) e fibra em detergente ácido (FDA), que conferem alta digestibilidade e valor nutritivo, apesar da menor oferta de fontes energéticas de degradabilidade lenta (Brown, 1993), o que possibilita a produção de até oito quilos diários de leite (Ferreira, 2004). Por sua vez, a silagem de milho apresenta menor quantidade de proteína bruta, mas maior valor energético, decorrente do amido e da FDN. Dessa forma, a silagem de milho oferece mais substrato energético, mas é desequilibrada quanto ao teor de proteína, o que sustenta a produção de cinco quilos diários de leite (Ferreira, 2004).
Outra explicação que também pode ser dada para a diferença na produção de leite das primíparas é o estresse do início da lactação. Assim, as vacas que pariram durante a estação chuvosa permaneceram alimentando-se de pastagens, enquanto que as que pariram durante a estação seca passaram a ser alimentadas no cocho, com silagem de milho. $O$ estresse inicial do confinamento, a competição com outras vacas dentro do rebanho e a adaptação ao novo volumoso oferecido, podem ter contribuído para a menor produção de leite durante o início da lactação, uma vez que as primíparas não foram manejadas como um lote de produção separado.

$\mathrm{O}$ período de serviço foi menor $(\mathrm{P}<0,05)$ na estação seca, 132,02 $\pm 91,94$ dias, do que na

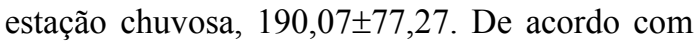
Ferreira (2004), o início da estação chuvosa é a época de maior valor nutritivo das pastagens, capaz de possibilitar elevada produção de leite. Entretanto, o valor energético da dieta é baixo e não permite que o animal recupere sua condição corporal antes do terço final da lactação. Durante a estação seca, a suplementação dos animais com silagem de milho permite curto período de balanço energético positivo, após o pico da lactação. Assim, a alta disponibilidade energética pode ter sido a explicação para essa condição. Os valores encontrados para o período de serviço, nesse trabalho, estão acima dos encontrados na literatura para primíparas mestiças, que variam de 100 a 120 dias (Lara, 1985; Vasconcelos et al., 1989). 
O intervalo de partos teve o mesmo comportamento do período de serviço. Durante a estação seca, o intervalo de partos foi de $13,90 \pm 3,06$ meses, sendo menor $(\mathrm{P}<0,05)$ que o das vacas que pariram no início da estação chuvosa, 15,84 $\pm 2,58$ meses, cujos valores são semelhantes aos descritos por Junqueira Filho et al. (1992). Segundo esse autor, houve efeito da origem das vacas mestiças sobre o intervalo de partos. Vacas mestiças oriundas do sistema da Embrapa/Gado de leite apresentaram menor intervalo de partos $(\mathrm{P}<0,05)$, de $13,8 \pm 0,3$ meses, em relação ao das oriundas de outros sistemas de

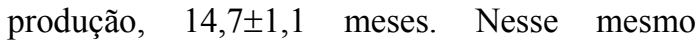
trabalho, primíparas de diferentes composições genéticas apresentaram intervalo de partos de 14,13 meses. Os resultados encontrados, no presente trabalho, diferiram daqueles observados por Freitas et al. (1980), que não observaram efeito da época do parto sobre o intervalo de partos. Durante a estação seca, o intervalo de partos foi de $478 \pm 12$ dias, semelhante $(\mathrm{P}>0,05)$ ao do verão, de $452 \pm 13$ dias.

Observou-se interação estação de parição versus base genética materna para a idade à cobrição e ao parto. Assim, as fêmeas da base genética Gir que pariram no verão apresentaram $(\mathrm{P}<0,05)$ idade à cobrição mais elevada (mais tardias) (Tab. 4). Possivelmente, a presença de animais mais tardios nesse grupo de fêmeas, de menor desenvolvimento ponderal durante a recria, fez com que os mesmos só alcançassem o peso à cobrição durante a segunda estação de monta realizada.

Tabela 4. Valores médios da idade à cobrição e ao parto, de acordo com a base genética materna e época do parto

\begin{tabular}{llcc}
\hline Variável & \multicolumn{1}{c}{ Época do parto } & Gir & Guzerá \\
\hline \multirow{2}{*}{ Idade à cobrição } & Estação seca & $22,23 \pm 2,35 \mathrm{aA}$ & $22,27 \pm 1,57 \mathrm{aA}$ \\
& Estação chuvosa & $25,98 \pm 3,59 \mathrm{bB}$ & $22,49 \pm 5,15 \mathrm{aA}$ \\
\multirow{2}{*}{ Idade ao parto } & Estação seca & $31,72 \pm 2,33 \mathrm{aA}$ & $31,59 \pm 1,38 \mathrm{aA}$ \\
& Estação chuvosa & $35,54 \pm 3,74 \mathrm{bB}$ & $31,97 \pm 5,27 \mathrm{aA}$ \\
\hline
\end{tabular}

Médias na mesma linha, para a mesma variável, seguidas de letras minúsculas distintas, diferem entre si $(\mathrm{P}<0,05)$ pelo teste t de Student.

Médias na mesma coluna, para a mesma variável, seguidas de letras maiúsculas distintas, diferem entre si $(\mathrm{P}<0,05)$ pelo teste $t$ de Student.

Os valores encontrados para a idade à primeira cobrição aproximam-se dos descritos por Teodoro et al. (1984), que relataram idade de 25,41 meses. Os resultados encontrados para a idade ao primeiro parto são semelhantes aos descritos por Freitas et al. (2003), que relataram valor de 31 meses para vacas mestiças F1 Holandês x Zebu. Entretanto, diversos trabalhos da literatura nacional relataram idades ao primeiro parto maiores do que os valores observados neste trabalho, variando em torno de 40 meses (Freitas et al., 1980; Junqueira Filho et al., 1992). Junqueira Filho et al. (1992), ao trabalharem com vacas mestiças F1 de duas origens diferentes, observaram efeito da origem sobre a idade ao primeiro parto. Os animais, nascidos dentro do sistema de produção estudado por eles, tiveram idade ao primeiro parto de $34,6 \pm 1,5$ meses, menor $(\mathrm{P}<0,05)$ do que a das fêmeas nascidas em outras propriedades $(45,4 \pm 0,8$ meses $)$. Nesse caso, as diferenças podem ser decorrentes do desenvolvimento dos animais entre a desmama e a entrada no sistema de produção.

A produção total de leite durante a primeira lactação, a produção média diária de leite, a duração da lactação e a produção de leite por dia de intervalo de partos diferiram $(\mathrm{P}<0,05)$ entre as bases genéticas utilizadas (Tab. 5). A produção de leite na primeira lactação foi maior $(\mathrm{P}<0,05)$ para as primíparas de base genética Gir, $2276,15 \pm 656,47 \mathrm{~kg}$, em relação às de base genética Guzerá, $1733,74 \pm 678,41 \mathrm{~kg}$.

Os valores encontrados são menores que os relatados na literatura. Freitas et al. (2001) encontraram produção de leite de $3673 \mathrm{~kg}$ em 269 dias de lactação para mestiças F1 Holandês x Gir. Madalena et al. (1990), ao avaliarem vacas mestiças F1 Holandês $\mathrm{x}$ Guzerá, também relataram valores maiores do que os encontrados neste trabalho. Segundo esses autores, a produção de leite de $2953 \mathrm{~kg}$ em 305 dias de 
lactação, para um nível de manejo nutricional alto, foi maior do que os $2636 \mathrm{~kg}$ de leite produzidos em 375 dias de lactação, em um nível de manejo nutricional baixo.

A duração da lactação também variou em função da base genética materna. Dessa forma, as fêmeas de base Gir apresentaram maior $(\mathrm{P}<0,05)$

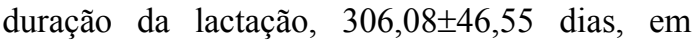
relação às de base Guzerá, 265,62 $\pm 67,11$ dias. Pode-se explicar a menor duração da lactação em função da menor produção de leite durante a lactação ou, ainda, pela produção média de leite durante a lactação, que foi menor $(\mathrm{P}<0,05)$ para as fêmeas de base Guzerá $(6,53 \pm 2,10 \mathrm{~kg} / \mathrm{dia})$ em relação às de base Gir $(7,39 \pm 1,67 \mathrm{~kg} /$ dia $)$. Outra explicação possível é o efeito do período de serviço, que apesar de não ser diferente $(\mathrm{P}>0,05)$ entre as bases genéticas, pode ter influído na duração da lactação, uma vez que o encerramento ocorreu 60 dias antes do próximo parto previsto.

Tabela 5. Valores médios de variáveis biométricas, produtivas e reprodutivas de primíparas mestiças F1 Holandês x Zebu

\begin{tabular}{lcc}
\hline Variável & Gir & Guzerá \\
\hline PC (kg) & $370,74 \pm 34,26$ & $362,63 \pm 33,25$ \\
PP (kg) & $447,70 \pm 45,93$ & $461,08 \pm 47,95$ \\
GPG (kg) & $78,46 \pm 52,90$ & $98,45 \pm 36,69$ \\
ECCP (3-5) & $3,80 \pm 0,43$ & $4,07 \pm 0,47$ \\
PL100 (kg) & $880,34 \pm 210,33$ & $731,49 \pm 205,51$ \\
PL (kg) & $2276,15 \pm 656,47 \mathrm{a}$ & $1733,74 \pm 678,41 \mathrm{~b}$ \\
PLM (kg/dia) & $7,39 \pm 1,67 \mathrm{a}$ & $6,53 \pm 2,10 \mathrm{~b}$ \\
DL (dias) & $306,08 \pm 46,55 \mathrm{a}$ & $265,62 \pm 67,11 \mathrm{~b}$ \\
PS (dias) & $172,13 \pm 97,92$ & $133,19 \pm 79,51$ \\
IDP (meses) & $15,24 \pm 3,26$ & $13,94 \pm 2,65$ \\
PLDIP (kg/dia) & $5,06 \pm 1,38 \mathrm{a}$ & $4,37 \pm 1,68 \mathrm{~b}$ \\
\hline
\end{tabular}

Médias na mesma linha seguidas de letras distintas diferem entre si pelo teste F.

PC-peso à cobrição; PP-peso ao parto; GPG-ganho de peso durante a gestação; ECCP-escore da condição corporal ao parto; PL100-produção de leite nos primeiros 100 dias de lactação; PL-produção de leite na primeira lactação; PLM-produção de leite média; PS-período de serviço; IDP-intervalo de partos; PLDIP-produção de leite por dia de intervalo de partos.

As vacas de base Gir também apresentaram maior $(\mathrm{P}<0,05)$ produção de leite por dia de intervalo de partos $(5,06 \pm 1,38 \mathrm{~kg})$ do que as de base Guzerá $(4,37 \pm 1,68 \mathrm{~kg})$. Lemos et al. (1997) verificaram produção de leite de $8,9 \pm 0,65 \mathrm{~kg}$ por dia de intervalo de partos para vacas F1 Holandês x Gir, e Madalena et al. (1990) encontraram produções de leite de 7,89 e 5,06kg por dia de intervalo de partos, para vacas F1 Holandês x Guzerá, submetidas a diferentes níveis de manejo nutricional, a saber, alto e baixo, respectivamente. Recentemente, Saulytis (2004), ao avaliar o desempenho de vacas mestiças F1 Holandês x Zebu de diferentes ordens de parto e três diferentes bases genéticas maternas (Gir, Guzerá e Indubrasilada), não encontrou diferença na produção de leite segundo a base genética Gir e Guzerá. Entretanto, as fêmeas de base genética Guzerá apresentaram maior $(\mathrm{P}<0,05)$ peso ao parto $(466,27 \pm 48,52 \mathrm{~kg})$ que as de base genética Gir
$(443,05 \pm 46,31 \mathrm{~kg})$. Esses resultados, juntamente com os aqui apresentados para as vacas de primeira lactação, enfatizam que diferenças no peso à idade adulta de vacas F1, de diferentes bases genéticas, podem resultar em diferentes recomendações de pesos e idades à cobrição.

Variações no peso ao parto, produção de leite, período de serviço e intervalo de partos em vacas primíparas podem ocorrer devido a efeitos de base genética materna e época do ano, portanto devemos considerar essas variáveis ao avaliar o desempenho dessa categoria animal.

\section{REFERÊNCIAS BIBLIOGRÁFICAS}

BROWN, W.F. Cane molasses and cottonseed meal supplementation of ammoniated tropical grass hay for yearlings cattle. J. Anim. Sci., v.71, p.3451-3457, 1993. 
FERREIRA, J.J. Alimentação de bovinos mestiços leiteiros. Inf. Agropec., v.25, p.64-72, 2004.

FREITAS, A.F.; MADALENA, F.E.; MARTINEZ, M. L. Idade ao primeiro parto e intervalo entre partos de vacas HPB e mestiças HPB:Gir. Pesq. Agropec. Bras., v.15, p.101-105, 1980 .

FREITAS, M.S.; DURÃES, M.C.; FREITAS, A.F. et al. Comparação da produção de gordura e da duração da lactação entre cinco "graus de sangue" originados de cruzamentos entre Holandês e Gir em Minas Gerais. Arq. Bras. Med. Vet. Zootec., v.53, p.708-713, 2001.

JUNQUEIRA FILHO, G.N.; VERNEQUE, R.S.; LEMOS, A.M. et al. Fatores fisiológicos e de meio sobre a produção de leite por vacas mestiças leiteiras no CNPGL/Embrapa. Pesq. Agropec. Bras., v.27, p.153-162, 1992.

LEMOS, A.M.; VERNEQUE, R.S.; TEODORO, R.L. et al. Efeito da estratégia de cruzamento sobre características produtivas e reprodutivas em vacas do sistema mestiço do CNPGLEmbrapa. Rev. Bras. Zootec., v.26, p.704-708, 1997.

LARA, J.L.R. Alguns aspectos reprodutivos de um rebanho leiteiro no periodo pós-parto. 1985. 58f. Dissertação (Mestrado em Medicina Veterinária). Escola de Veterinária, Universidade Federal de Minas Gerias, Belo Horizonte.
MADALENA, F.E.; LEMOS, A.M.; TEODORO, R.L. et al. Dairy production and reproduction in Holstein-Friesian and Guzera crosses. J. Dairy Sci., v.73, p.1872-1886, 1990.

RUAS, J.R.M. Concentrações plasmáticas de colesterol, glicose e uréia em vacas zebuínas em relação à condição corporal e ao status reprodutivo. Rev. Bras. Zootec., v.29, supl., p.2036-2042, 2000.

SAULYTIS, F.C.F. Efeito da origem, base genética materna zebuína, ordem e época de ocorrência dos partos de fêmeas F1 Holandêszebu sobre variáveis biométricas, reprodutivas e produtivas. 2004. 108f. Dissertação (Mestrado em Medicina Veterinária). Escola de Veterinária, Universidade Federal de Minas Gerais, Belo Horizonte.

TEODORO, R.L.; LEMOS, A.M.; BARBOSA, R. T. et al. Comparative performance of six Holstein-Friesian x Guzera grades in Brazil. 2 traits related the onset the sexual function. Anim. Prod., v.38, p.165-170, 1984.

VASCONCELOS， J.L.M.; SILVA， H.M.; PEREIRA, C. S. et al. Aspectos fenotípicos do período de serviço em vacas leiteiras com diferentes frações de sangue Holandês. Arq. Bras. Med. Vet. Zootec., v.41, p.477-482, 1989.

VILELA, D. Perspectivas para a produção de leite no Brasil. In: SINLEITE, 2003. Anais... Lavras, 2003. p.225-248. 